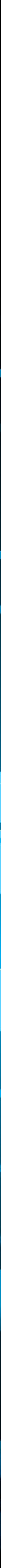




\section{TECNOLOGIA INCLUSIVA?}

\section{O blockchain tem potencial para melhorar o uso, a qualidade e o custo dos serviços financeiros à população brasileira, mas ainda há desafios técnicos, operacionais e de governança.}

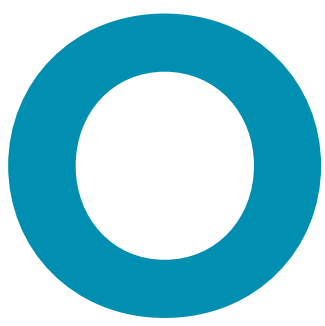

blockchain tem sido assunto de debates acalorados na sua aplicação em criptomoedas, como o bitcoin. Bem mais impactante que o bitcoin, a tecnologia que suporta o blockchain (ledger distribuído) traz inúmeras aplicações para empresas e governos. O blockchain já representa um ponto focal do pensamento sobre inovação. O Fórum Econômico Mundial (FEM) estima que, até $2027,10 \%$ do produto interno bruto (PIB) mundial será armazenado em plataformas usando tecnologia de blockchain. Paralelamente, os órgãos reguladores têm se mostrado interessados em inovações na área de tecnologia financeira (Fintech) para incentivar a competição e gerar mais inclusão. O blockchain poderia se tornar uma alavanca para a inclusão financeira?

\section{INOVAÇÃO COM ATORES NOVOS}

Os avanços da inclusão financeira têm sido expressivos nas últimas duas décadas, com o crescimento do papel dos correspondentes bancários e melhoras na legislação financeira. Em 2010, o Banco Central do Brasil passou a considerar a promoção da inclusão financeira entre seus objetivos estratégicos, dando ênfase a um foco histórico da instituição. Considerando as quatro funções tradicionais de bancos (depósitos, créditos, pagamentos e seguros), o Brasil está à frente dos outros países da América Latina na oferta desses produtos, mas atrás de outros emergentes da Ásia e dos países desenvolvidos. Se o acesso a serviços financeiros é quase universal ( $86 \%$ da população adulta tinha relacionamento bancário em 2017, contra 61\% em 2005), o uso, a qualidade e o custo dos serviços não são sempre satisfatórios (apenas 31\% dos cartões de débito emitidos são considerados ativos, segundo o Banco Central).

Novas tecnologias chegam nesse momento de intensa reflexão sobre o papel das instituições financeiras tradicionais na sociedade. A inovação está vindo de três tipos de atores: os tradicionais bancos, com orçamentos amplos em tecnologia; novos entrantes (as Fintech), com soluções mais ágeis, reatividade grande e, até agora, foco em nichos subatendidos; e os setores não bancários, como varejo e mídia social, que apresentam potencial significativo de disrupção, vistos o tamanho, o poder de fogo e a base de clientes ativos. Para todos esses atores, o desafio da inovação é grande. 


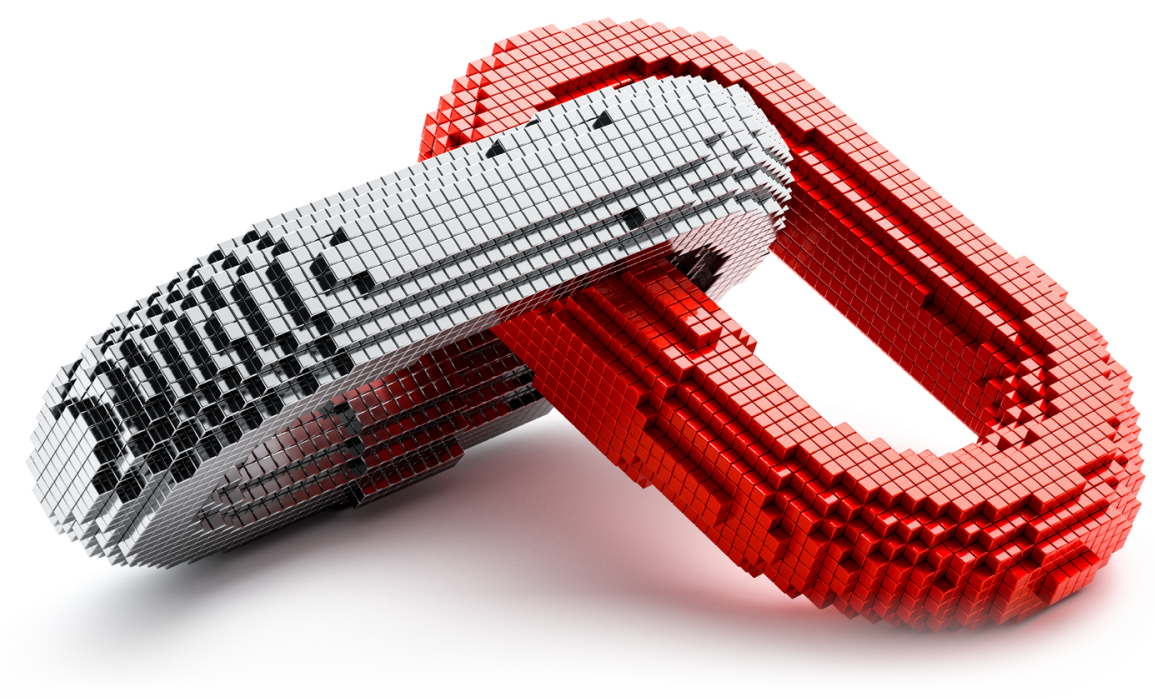

Embora a inovação financeira não seja um fenômeno recente, a tendência acelerou-se nos últimos anos, por conta do barateamento da tecnologia e da ubiquidade do celular, que permite interação permanente com o cliente e sem intermediários. A digitalização da economia e o uso de dados têm reduzido a necessidade de agências bancárias e de contatos personalizados por meio de bancos. No Brasil, o número de agências bancárias atingiu o pico em 2014 e tem decrescido desde então a uma taxa de $3 \%$ ao ano, com previsão de mais fechamentos nos próximos anos.

A inovação financeira tem como objetivos tornar as instituições financeiras mais eficientes, reduzir riscos e também atender a um número maior de brasileiros com serviços financeiros de qualidade. O setor de pagamentos tem sido muito atuante com empresas recém-chegadas como PagSeguro, Izettle e SumUp ganhando participação de mercado por meio de ofertas ágeis e preços mais atrativos. No lado do crédito, empresas como Geru e Creditas vêm oferecendo agilmente linhas de crédito a taxas inferiores em relação à média do mercado, graças a sistemas inteligentes de tratamento de dados. Nas finanças pessoais, o Guiabolso, por exemplo, tem atraído mais de três milhões de clientes com soluções inteligentes de gestão de metas financeiras. No aquecido setor de Insurtech (de empreendimentos tecnológicos de seguros), observamos o desenvolvimento da digitalização na distribuição e o uso maior de dados (big data) para a formação de apólices, prevenção e precificação customizada. Além de oferecerem

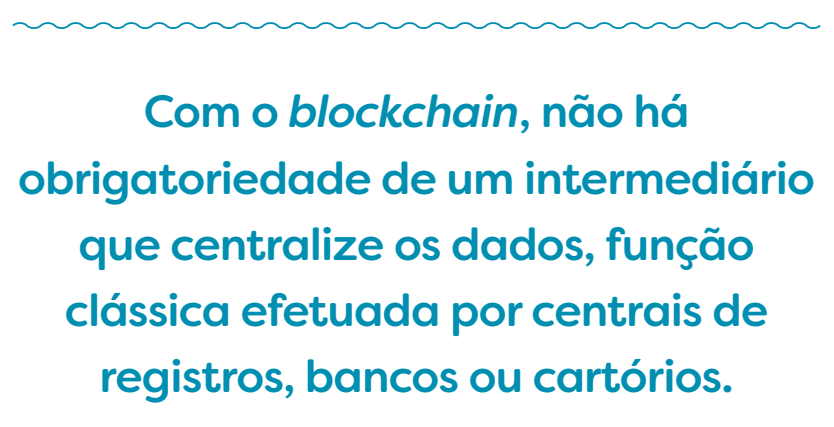

serviços de qualidade à totalidade da população, produtos e processos desenhados para a chamada base da pirâmide têm se provado bons negócios.

\section{AS APLICAÇÕES DO BLOCKCHAIN}

O blockchain faz parte dessa frente de inovação. A tecnologia de ledger distribuído é baseada na ideia de compartilhamento e verificação consensual dos dados, gerando imutabilidade e segurança. Essa tecnologia reduz a necessidade de um intermediário que centralize os dados, função clássica efetuada por centrais de registros, bancos ou cartórios. Os anos de 2015 e 2016 foram de difusão da tecnologia e da aprendizagem. Depois da euforia e da desilusão, o blockchain entrou em uma fase de implementação, com provas de conceitos sucedidas na fase de teste. A criptomoeda bitcoin, aplicação mais conhecida do ledger distribuído, 


\section{O blockchain pode compartilhar dados de credit scoring, facilitar remessas, simplificar cadastro e reduzir custos de compliance, entre outros benefícios potenciais.}

vem demonstrando a solidez tecnológica do conceito. Embora de maneira imperfeita, o bitcoin atende às três funções clássicas das moedas: meio de troca, reserva de valor e unidade de conta. O bitcoin tem atraído interesse como ativo financeiro pela ausência de correlação com mercados tradicionais, mas sua aceitação como moeda no mundo real continua limitada.

Em pesquisa realizada em 2018, o banco UBS catalogou os produtos lançados com blockchain mundialmente e identificou seis áreas de implementação da tecnologia em bancos: sistemas de negociação de balcão, pós-negociação de ativos financeiros, remessas, trade finance, cadastro de clientes (know your customer) e, naturalmente, criptomoedas. De maneira geral, o blockchain pode ser disruptivo em negócios que dependem de processos centralizados, que exigem um registro e em que a origem e posse de um ativo são elementos críticos.

No Brasil, ainda não foram lançados produtos no ramo financeiro com blockchain, mas vários projetos estão em análise e outros setores, como o agronegócio, já se beneficiam da tecnologia. Três segmentos chamam a atenção, com potenciais ganhos de eficiência e melhor inclusão. $\mathrm{Na}$ área de cadastro e compliance, a tecnologia pode servir para unificar os dados de clientes entre bancos, em uma atividade que apresenta pouco valor agregado e diferencial entre bancos, como já tem sido feito no projeto chamado Fingerprint, lançado por Itaú, Bradesco e B3. A consultoria Accenture, em relatório de 2017, estimou que o uso do blockchain poderia reduzir os custos de compliance de 30 a $50 \%$. Com a diminuição de custos administrativos, bancos poderão atender a um número maior de clientes. $\mathrm{Na}$ área de crédito, o blockchain poderia ser usado em sistemas completos e seguros de scoring, pontuação que indica o risco de cada cliente. A empresa Bloom, nos Estados Unidos, propõe um scoring de crédito descentralizado usando o blockchain, dando autonomia para clientes procurarem crédito na instituição que oferece os melhores termos. $\mathrm{Na}$ área de transferências internacionais, que permanece complexa, com taxas que podem chegar a $8 \%$ do valor transferido, existem também propostas. A Sociedade para as Telecomunicações Financeiras Interbancárias Mundiais (Swift) anunciou uma parceria com mais de 30 bancos globais e a International Business Machines (IBM). Em 2017, o Banco Bilbao Vizcaya Argentaria (BBVA) realizou a primeira remessa por blockchain entre Espanha e México, uma transação liquidada em segundos por um custo inferior ao dos sistemas tradicionais. Empresas como BitPesa, uma plataforma de câmbio e pagamento digital da e para a África, estimam que o blockchain pode reduzir o custo e o tempo de uma remessa em até $90 \%$.

\section{DESAFIOS}

O Brasil tem apresentado exemplos de sucesso em regulação e tecnologia bancária, como os correspondentes bancários e o sistema brasileiro de pagamentos. Para que a inclusão financeira se intensifique, as inovações com blockchain têm grande potencial, ao trazerem mais comodidade, segurança e menos custo para o sistema e o usuário final. Subsistem algumas barreiras em torno do blockchain. A colaboração entre instituições financeiras e a interligação do blockchain com sistemas existentes são grandes desafios. Além das dificuldades operacionais e tecnológicas, ainda falta definir mecanismos de governança para o blockchain. Essas regras do jogo vão ditar quem tem acesso, quem valida, quem modifica e quem usa as informações no ledger. A nova governança do blockchain deve ser transparente, legítima e equilibrada para poder beneficiar a todos.

*Os fatos, relatos e opiniões destacados no artigo refletem exclusivamente a opinião do autor.

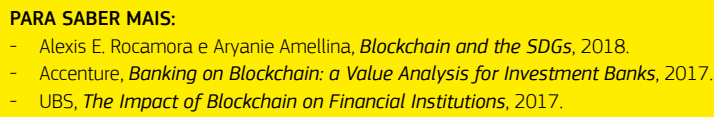

FREDERIC DE MARIZ > Diretor executivo do UBS Brasil > frederic.de-mariz@ubs.com 